\title{
Evangelizing Usability to 700 People: Strategies for Building a User-Centered Organizational Culture
}

\author{
Filipe Levi, Paulo Melo, Ubirajara de Lucena, \\ Cynthia Belleza, and José Arcoverde \\ CESAR - Recife Center for Advanced Studies and Systems \\ Rua Bione 220, Bairro do Recife, Recife, Brazil \\ ffilipe.levi, paulo.melo, ubirajara.junior, cynthia.belleza, \\ mabuse\} @cesar.org.br
}

\begin{abstract}
For the last three years, CESAR's user experience team has endeavored to build a user-centered organizational culture. In this report, we present some succeeding empirical strategies for evangelizing usability, in the hope that professionals in similar contexts might benefit from them.
\end{abstract}

Keywords: Usability evangelism, user-centered culture, ICT organizations.

\section{Introduction}

CESAR is a world-class private $\mathrm{R} \& \mathrm{D}$ institution that creates innovative products, processes and services using information and communication technologies. ${ }^{1}$ Although recently awarded as the most innovative Brazilian research institute ${ }^{2}$ and the best software services company in Brazil, ${ }^{3}$ CESAR grew out of a traditional faculty of Informatics and kept a strict technology-centered mind for a long time.

For the last three years, the company has maintained a user experience team assembling professionals from Design, Cognitive Psychology, and Computer Science. Our first job was to design the concept of and execute a usability factory [1] for the Central Bank of Brazil, promoting the social inclusion of young disadvantaged adults in the technology industry. Since then, we have been working in a wide range of domains, from web and desktop systems to mobile games, interactive TV, transportation and kiosks. Some of our clients include Samsung, Siemens, and Dell.

\section{Some Strategies}

Changing an organizational culture is neither simple nor rapid, and usability practitioners must exercise perseverance in an everyday effort. From our own experience, the following strategies have proven successful:

\footnotetext{
${ }^{1}$ More about CESAR at http://www.cesar.org.br

${ }^{2}$ The 2004 FINEP award for Most Innovative Research Institute in Brazil.

${ }^{3}$ The 2005 Info200 magazine award for Best Software Services Company. 
- Combine bottom-up and top-down evangelism. Make partners among colleagues and managers as well. Demonstrate the value of usability to the entire company.

- Talk to people about usability using their business or technical language. For instance, project managers might be interested in time and budget to perform usability techniques, while marketers might want to know about the benefits of a usable product to potential customers.

- Do not try to replace well-established things - such as processes, activities and roles. Instead, start by integrating new ones and demonstrating their value. More profitable practices will naturally replace old ones.

- Plan your steps and be patient. Consistent changes often happen gradually, not at once. Every little achievement has the potential to open bigger opportunities for you to do a better job.

- Collect metrics of your work continually. It helps a lot when you are given a chance to demonstrate the return of investment in usability or to estimate resources for user-centered activities within a project.

- If possible, work in teams or talk to other usability practitioners at your company. Discussions enrich your opinions and improve your decision-making skills.

- Work close to the engineering people, not apart from them. Be careful not to give the impression of being an isolated group of inaccessible specialists.

- Extend your professional network. Establish partnership with other companies and share experiences with usability professionals from your ecosystem.

\section{Main Achievements and New Challenges}

CESAR is now completing the full integration of usability with its institutional software development process, what specialists argue to be the goal of late-stage evangelism efforts in a company [2]. The process - which adopts an iterative and incremental development approach - has just included some user-centered methods: user research, rapid prototyping, usability consultancy, and user testing, during the phases of, respectively, requirements, analysis \& design, coding and testing.

Our next goal is to include field studies with users starting at the pre-sale phase of our software development process. We have noticed that most of our clients do not know enough about the real problems faced by their users and come to CESAR asking for solutions which might not actually address those problems. We are also engaged in applying qualitative methods during the maintenance phase, after our products have been released, in order to continually improve the user experience.

\section{References}

1. Levi, F., Melo, P., Lucena, U.: Accessibility Implementation Planning for Large Governmental Websites: a Case Study. In: Proceedings of the 4th Latin American Web Congress, Cholula, Mexico, pp. 113-118 (2006)

2. Nielsen, J.: Jakob Nielsen's Alertbox: Evangelizing Usability: Change Your Strategy at the Halfway Point (2005), http://www.useit.com/alertbox/20050328.html 